\title{
GAMBAR WAYANG KARYA SURIPNO DARI PERSPEKTIF RASA DALAM KEBUDAYAAN JAWA
}

\author{
Feri Widiyanto \\ Fakultas Seni Rupa dan Desain ISI Surakarta \\ feriwidiyanto@gmail.com
}

\begin{abstract}
Wayang purwa is a Javanese art and culture product. The existence of wayang purwa in Javanese culture is very influential on the life of Javanese society. Variants of wayang that can be found today is one of them is a puppet image made by Suripno. The process of creating Suripno puppet shapes also can not be separated from the experience and knowledge of Suripno as the maker. The method used in this study is an ethnographic method that emphasizes the observation of behavior, interviews and artifacts.

Suripno's wayang pictures are an expression of his inward appreciation to the characters, mythology and the wayang story. Viewed from the perspective of taste in the Javanese culture aesthetics Suripno puppet pictures are a non-sensory aesthetic based on sense of appreciation, protection, tranquility, evenness and irony.
\end{abstract}

Keywords: Suripno, puppet image, aesthetics, taste, Javanese culture.

\section{ABSTRAK}

Wayang purwa merupakan produk seni budaya Jawa. Eksistensi wayang purwa dalam kebudayaan Jawa sangat berpengaruh pada kehidupan masyarakat Jawa. Varian wayang yang dapat dijumpai saat ini salah satunya adalah gambar wayang yang dibuat oleh Suripno. Proses terciptanya gambar-gambar wayang karya Suripno juga tidak lepas dari pengalaman dan pengetahuan Suripno sebagai pembuatnya. Metode yang dipakai dalam penelitian ini merupakan metode etnografi yang ditekankan pada pengamatan perilaku, wawancara dan artefak.

Gambar-gambar wayang karya Suripno merupakan ekspresi penghayatan batiniahnya pada tokoh, mitologi dan kisah wayang. Dilihat dari perspektif rasa dalam kebudayaan Jawa estetika gambar-gambar wayang karya Suripno merupakan estetika non inderawi yang berlandaskan pada rasa penghayatan, pengayoman, ketentraman, kejelataan bahkan ironi.

Kata kunci: Suripno, gambar wayang, estetika, rasa, kebudayaan Jawa.

\section{PENDAHULUAN}

Wayang (wayang purwa) mem -punyai peran penting dalam kehidupan masyarakat Jawa tradisional karena di dalamnya termuat suri tauladan bagi kehidupan (Subagya,: 2013: 266). Masyarakat Jawa tradi- sional mempercayai wayang sebagai gambaran para leluhurnya, oleh sebab itu wayang mempunyai pengaruh yang kuat dalam kehidupan sehari-hari masyarakat Jawa tradisional (Subagya,: 2013: 266). Nilainilai yang terkandung di dalam wa- 
yang (di antaranya pada simbol-simbol yang digunakan) dijunjung tinggi sebagai simbol identitas dan idealitas manusia Jawa, baik oleh raja sampai pada masyarakat biasa $\mathrm{Ri}$ yanto, 2007: 13). Selain sebagai tontonan dan tuntunan wayang juga mempunyai muatan mistik, sesuai dengan pola pikir, spiritualisme, masyarakat Jawa tradisional (Stange, 1998).

Penafsiran atas keberadaan dan eksistensi wayang pun terus berjalan sesuai dengan pemahaman masyarakat yang berbeda-beda. Wa -yang saat ini, selain dalam bentuk tradisionalnya, juga hadir di masyarakat dengan kemasan yang baru, ikon tokoh-tokoh pewayangan muncul pada kaos, sepatu, dan tas (Tanudjaya, 2004: 47). Kini pertunjukan wayang juga dapat dinikmati lewat televisi, radio, dan internet (Rusputranto, 2007).

Wayang, baik boneka wayang maupun gelar pertunjukannya (dalam pertunjukan langsung maupun lewat media massa), oleh masyarakat sekarang umumnya didudukkan sebagai sekadar tontonan. Meski demikian, di lingkungan Karaton Kasunanan Surakarta masih ada sebagian masyarakat Jawa yang memuja wayang menurut makna dan fungsi baku dari karaton. Seba- gian masyarakat Jawa tersebut sangat menjunjung nilai tradisi dengan tetap menerapkaan ajaran, aturan dan tata hidup sesuai dengan ajaran karaton.

Di dalam lingkungan primordial karaton terdapat berbagai lapisan golongan menurut status. Raja berada pada posisi puncak dari semua golongan, oleh sebab itu raja dianggap mempunyai kekuasaan penuh atas segalanya (Kuntowidjoyo, 2004: 22). Abdi dalem, yang hidup di dalam lingkungan karaton, dengan patuh melayani segala kebutuhan raja (beserta para ke-rabatnya) dan karaton. Selain melayani kebutuhan raja, abdi dalem pun mempunyai kewajiban untuk tetap melestarikan tradisi dan budaya Jawa tradisional (Mahardika, 2011).

Pemahaman abdi dalem pada tradisi dan budaya Jawa sangat kuat karena pada dasarnya abdi dalem adalah orang yang tunduk dan patuh pada segala nilai tradisi Jawa dengan hadirnya simbol Raja dan Karaton sebagai pengaturnya (Kuntowidjoyo, 2004: 22). Ketika sistem kerajaan tergantikan dengan sistem pemerintahan modern, peran abdi dalem tidak banyak berubah (Sutrisno, 2009). Kehidupan dan kegiatan sehari-hari di lingkungan karaton memberikan bekal pemahaman kuat 
terhadap tradisi dan budaya Jawa (tradisional) bagi abdi dalem.

Wujud kesetiaan abdi dalem dapat kita temukan pada figur seorang mantan abdi dalem Karaton Kasunanan Surakarta yang bernama Suripno (79 tahun). Suripno, yang saat ini hidup di pinggiran Pasar Klewer, merupakan figur masyarakat Jawa tradisional yang masih setia pada keberadaan dan kebesaran Karaton Kasunanan Surakarta. Saat ini Suripno telah berhenti menjadi abdi dalem karaton dan menduduki posisi sebagai masyarakat umum, meskipun demikian Suripno masih nguri-uri (melestarikan) nilai tradisi dan budaya Jawa tradisional (karaton). Sesuai dengan latar belakangnya sebagai bagian dari masyarakat Jawa tradisional, mantan abdi dalem karaton, mitologi wayang menjadi bagian penting dalam kehidupannya.

Suripno gemar menggambar figur-figur boneka wayang (purwa). Bagi Suripno kegiatan menggambar wayang merupakan wujud rasa hormatnya pada nenek moyang yang di anggapnya adiluhung.

Namun anehnya bentuk dan gambar wayang Suripno agak berbeda dengan gambar figur boneka wayang purwa yang umum dikenal masyarakat Jawa. Gambar figur boneka wayang yang dibuat Suripno terkesan jauh lebih sederhana, tidak seindah visual boneka wayang yang banyak dijumpai di panggung-panggung per-tunjukan wayang purwa. Gambar wayang karya Suripno merupakan ekspresi visual (estetika) masyarakat di luar tembok karaton yang memiliki pemahaman sendiri terhadap visual wayang. Setyawan, dalam tulisannya yang berjudul Wayang Rajakaya: Kisah Sapi, Padang Rumput, dan Yu Segawon, menyebutkan bahwa penggambaran wayang gaya pedesaan lebih menekankan bagai-mana figur tokoh yang digambarkan cukup hanya tertangkap sebagai tokoh dalam cerita yang dimaksud (Setyawan, 2007:34). Demikian pula gambar-gambar wayang karya Suripno; cukup hanya tertangkap kesan tokoh figur wayang yang digambarkan.

Menurut Suripno, setiap karya yang dikerjakannya mempunyai pesan, pepeling, untuk masyarakat (dalam wawancara dengan Suripno, 2014). Pepeling tentang nilai luhur tradisi dan budaya Jawa. Suripno berharap setiap karyanya bisa menjadi "tontonan" yang dapat menentramkan hati bagi para penikmat karya-karyanya. Gambar - gambar wayang karya Suripno sangat sederhana. Ditorehkan pada triplek bekas, kertas, spanduk bekas atau 
kardus; sesuai dengan kondisi ekonomi Suripno. Berbeda dengan bahan baku pembuatan wayang purwa umumnya yang harus memakai bahan kulit sapi atau kerbau. Gambar wayang yang dikerjakan Suripno mempunyai karakteristik tersendiri. Gambar wayang karya Suripno terlepas dari pakem visual wayang yang biasa dijumpai dalam pertunjukan wayang purwa.

Pada gambar-gambar wayang karya Suripno dapat ditemukan coretan-coretan, bekas rokok atau lainnya yang secara tidak sengaja menodai, mengotori karya-karya tersebut. Karya Suripno yang muncul dengan tampilan kotor dan bebas memberikan sebuah keunikan tersendiri.

Pada usia 79 tahun (sekarang) Suripno bertahan untuk tetap berkarya dengan kondisi kehidupan yang terbatas, sebagai pelaku seni tradisi yang kurang mendapatkan apresiasi. Karya dan kehidupan Suripno berbeda dengan keberadaan pelaku seni tradisi Indonesia lainnya, seperti Masmundari, Citro Waluyo, dan Nyoman Lempad yang mendapatkan apresiasi di dunia seni rupa Indonesia. Padahal keunikan gambar wayang karya Suripno jika dikaji secara mendalam dapat menjadi sumbangan terhadap kajian ke- senirupaan, khususnya dialektika wa -cana seni tradisi di Indonesia.

\section{Metodologi Penelitian}

Penelitian ini merupakan penelitian kualitatif dengan menggunakan metode etnografi.. Etnografi merupakan pekerjaan mendeskripsikan suatu kebudayaan. Tujuan utama aktivitas ini adalah untuk memahami suatu pandangan hidup dari sudut pandang informan yang diteliti (Spradley, 2006: 3). Fokus utama penelitian ini adalah artefak budaya gambar wayang karya Suripno. Etnografer membuat kesimpulan budaya dari tiga sumber: (1) yang dikatakan orang, (2) dari cara orang bertindak; dan (3) dari berbagai artefak yang digunakan orang (Spradley, 2006: 11). Dengan meneliti artefak, melakukan wawancara dan mengamati perilaku.

\section{PEMBAHASAN}

Proses penciptaan karya (gambar-gambar wayang) yang dilakukan Suripno tidak lepas dari pengalaman hidup dan pengaruh lingkungan sekitarnya. Suripno lahir pada tahun 1936 di dusun Geneng, Bekonang, Sukoharjo. Lingkungan tempat tinggal Suripno semasa kecil merupakan lingkungan dengan tradisi dan budaya Jawa yang kuat. Semasa kecil 
Suripno sudah gemar menyaksikan pementasan wayang dan ketika menempuh pendidikan SR (Sekolah Rakyat) maka Suripno mulai menggambar wayang.

Pengaruh tradisi dan budaya di lingkungan tempat tinggalnya membuat Suripno berhasrat mendalami budaya Jawa melalui pilihannya mengabdi di karaton. Suripno mulai mengabdi di Karaton Kasunan pada tahun 1971 bertugas sebagai penjaga pintu Jalatunda. Ketika mengabdi di karaton, Suripno juga bertugas sebagai pelayan, penghatur sesaji dan sebagai berugas dalam urusan kebersihan. Suripno juga sebagai abdi dalem canthang balung.

Kesetiaan dan totalitas pengabdian Suripno pada karaton dan raja membuat dirinya dikenal sebagai abdi kinasih. Suripno pada awal kepemimpinan PB XIII berhenti sebagai abdi dalem. Setelah tidak lagi mengabdi di karaton Suripno masih tinggal di seputar karaton untuk mengharap berkah (ngalap berkah) karaton. Upaya Suripno ngalap berkah dilakukan dengan cara menggambar wayang.

Visualisasi gambar-gambar wa -yang karya Suripno mengarah pada visual wayang kulit purwa gaya Surakarta. Suripno mengakui bahwa gambar wayang karyanya merupakan hasil dari belajar meniru gambar wayang gaya Surakarta yang didapat dari buku (wawancara Suripno, 13 April 2014).

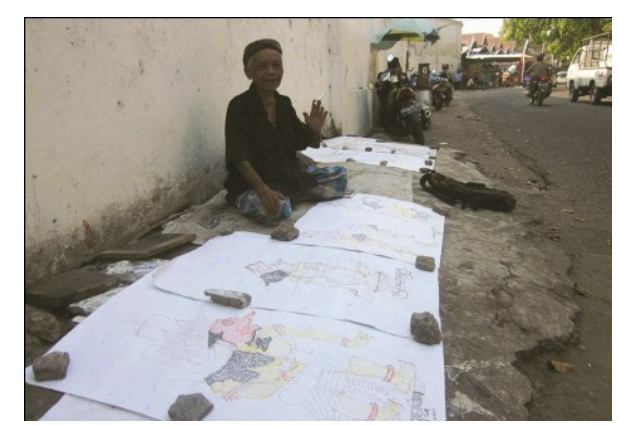

Gambar 1.

Suripno sedang menggelar gambargambarnya di tepi jalan Supit Urang Karaton Kasunanan Surakarta.

Meski meniru bentuk wayang kulit purwa gaya Surakarta tetapi eksekusi visual gambar wayang karya Suripno berbeda.. Alat dan bahan yang dipakai Suripno jauh dari aturan baku pembuatan wayang kulit purwa gaya Surakarta. Suripno megunakan alat dan bahan seperti: kertas, triplek, spanduk, cat besi, kuas dan spidol. Secara keseluruhan gambar wayang karya Suripno memang mempunyai arah gambar wayang kulit purwa tetapi ada keterbatasan teknik pembuatan (wawancara Suripno, 13 April 2014).

Suripno menggambarkan keberadaan titisan sang pembawa ketentraman dunia (Dewa Wisnu) mela 
-lui figur Kresna pada karya tersebut (wawancara Suripno, 30 Maret 20 14).

Kresna niku titisane Sang Hyang Wisnu ingkang gawe tentreming jagad. Supaya bisa nglungakake Bathara Kala ling gawe eleking jagad. Mula gandengan ta, eneng elek, eneng apik (wawancara Suripno, 14 Februari 2015).

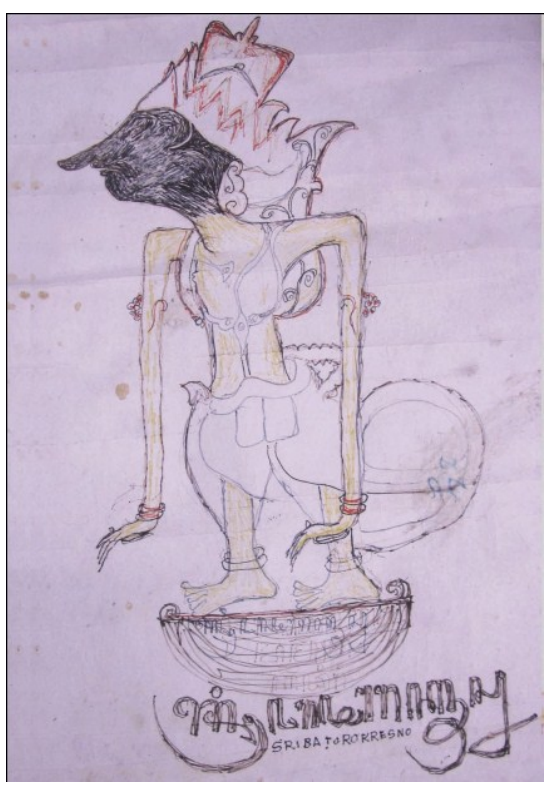

Gambar 2

Kresna sang Pangayom, Spidol pada kertas, $50 \mathrm{~cm} \times 70 \mathrm{~cm}, 2014$

(Dokumentasi foto Feri Widiyanto, 2014)

Menurut Suripno, Kresna adalah titisan Dewa Wisnu sang pembawa ketentraman bagi dunia, keberadaan Kresna di dunia dapat mengusir Batara Kala yang menjadi perusak. Batara Kala dan Wisnu ada -lah perwujudan baik dan buruk. Kresna memiliki wahyu dari Kahyang -an untuk memberi pertolongan pada setiap orang yang membutuhkan.

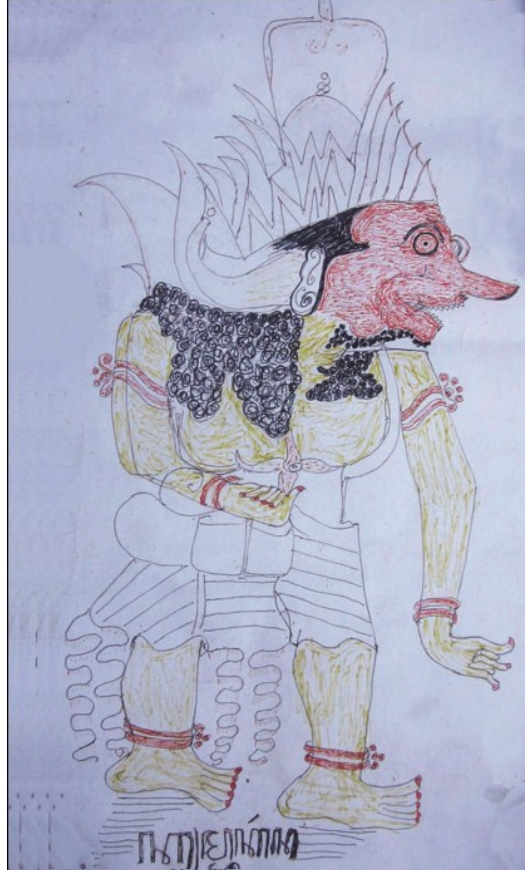

Gambar 3

Sang Ksatria Alengka, Spidol pada kertas, $50 \mathrm{~cm} \times 70 \mathrm{~cm}, 2014$

(Dokumentasi foto Feri Widiyanto, 2014)

Kumbakarna yang berpihak pa -da tanah airnya dalam perang, bagi Suripno merupakan wujud kerinduan -nya akan kehadiran seorang pemim -pin yang memperhatikan nasib rakyat kecil. Dalam sebuah wawancara, Suripno memberikan contoh mengenai seorang pemimpin yang menurutnya mewakili figur Kumbakarna. Kaya niku Ihe (Joko Widodo), ndek durung dadi presiden, niku wong mlarat-mlarat sak Sala ki digawekne omah kabeh, dikei duwit, Iha niku ngeki wujud tenan, niku watake Kumbakarna, wong sugih nanging eling nyang wong mlarat, amarga isaku duwe kaya ngene ki ya saka 
wong mlarat-mlarat (wawancara Suripno, 13 Maret 2015). Seperti keberadaan pemimpin saat ini; dulu sebelum menjadi pemimpin negara, Joko Widodo, menurut Suripno, merupakan seorang pemimpin yang sangat memperhatikan kehidupan rakyat kecil di kota Surakarta. Orang yang kekurangan (harta dan benda) diberi bantuan, itulah watak seorang Kum-bakarna: Orang kaya tapi sangat memperhatikan kehidupan orang yang kurang mampu. Karena ia sadar bahwa semua hasil yang didapatnya saat ini juga dari orangorang yang kurang mampu.

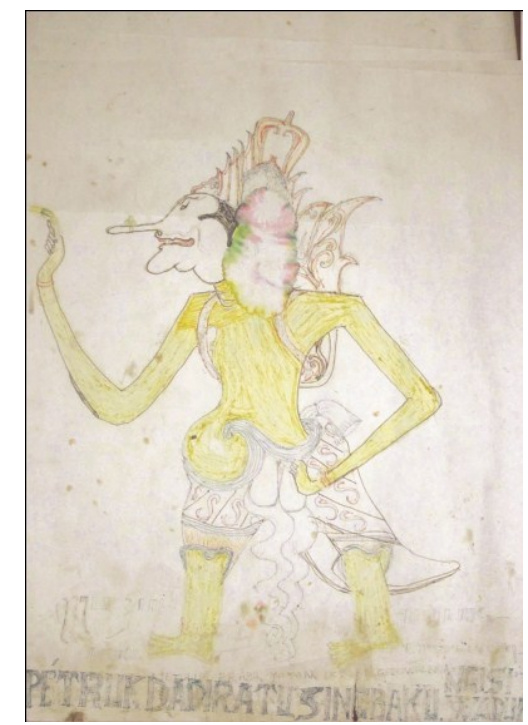

Gambar 4

Petruk dadi Ratu, Spidol pada kertas, $50 \mathrm{~cm}$ x $70 \mathrm{~cm}, 2014$.

(Dokumentasi foto Feri Widiyanto, 2014)

Gambar wayang karya Suripno yang berjudul Petruk dadi ratu menceritakan tokoh Petruk yang tiba-tiba menjadi seorang raja. Lha ngono kanggonan jimat layang Kalimasadha. ora ngono ora bisa dadi ratu (wawancara Suripno, 30 Maret 20 15). Petruk bisa menjadi seorang raja karena kesaktian Jamus Kalimasada tetapi Petruk tidak seperti figur raja lainnya yang mempunyai harta benda dan kekuasan, karena sebenarnya Petruk hanya seorang pengikut dan pelayan raja, Bagi $\mathrm{Pe}-$ truk menjadi raja yang paling penting adalah mencukupi kebutuhannya (memenuhi isi perut). Sing baku ngisi waduk, yang penting mengisi perut (wawancara Suripno, 30 Maret 2015).

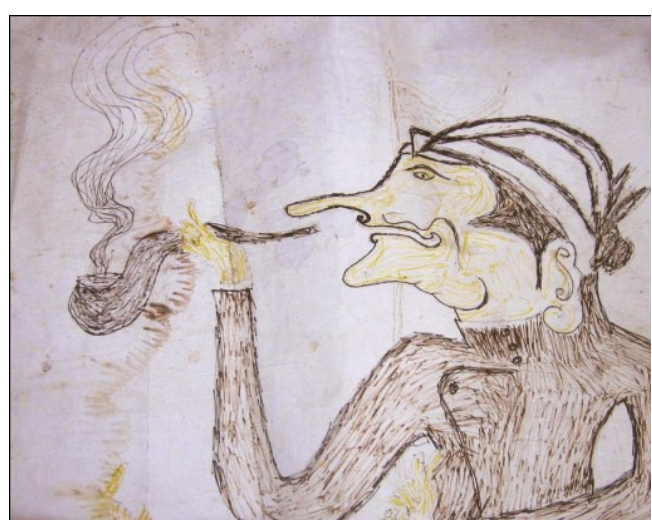

Gambar 5.

Petruk Nglaras, Spidol pada Kertas, $70 \mathrm{~cm}$ x $50 \mathrm{~cm}, 2014$ (Dokumentasi foto oleh: Feri Widiyanto, 2014)

Petruk yang sedang bersantai (nglaras) sambil menikmati tembakau Petruk punika batur nanging diparingi gedhe dhuwur irung dawa 
tegese: longgar, bisa nyaring ala lan becik (wawancara Suripno, 1 Juli 20 15). Petruk merupakan seorang pelayan namun memiliki kelapangan hati sebab Petruk dapat memilah antara hal baik dan buruk. Meski hanya sebagai pelayan, Petruk dapat menikmati kehidupan dengan perasaan tentram. Pipa menika larasing urip, uwong menika menawi sampun seger waras, tata tentrem, lan rejeki sempulur sing digoleki kuwi ora liya mung tentreming kaluwarga, mula laras (wawancara Suripno, 1 Juli 2015). Praktik menghisap tembakau adalah gambaran manusia yang sedang menikmati hidup. Ketika manusia telah mendapatkan kesehatan, ketentraman, dan rejeki maka tidak ada yang perlu dipersoalkan lagi selain ketentraman keluarga. Bagi Suripno cara menikmati hidup itu seperti orang yang sedang merokok dan mengunyah sirih. Kaya dene wong udud utawa nginang kuwi lak laras urip (wawancara Suripno, 1 Juli 2015).

Adegan percakapan antara Raden Sasikirana dan Petruk dalam karya ini terjadi pada masa setelah berakhirnya perang Baratayuda. Pada masa ini kehidupan telah berlangsung dengan damai dan sudah tidak ada lagi peperangan. Keberadaan negara Pringgodani setelah berakhirnya perang Baratayuda sedang dalam kondisi aman dan tentram. Rakyat di negara tersebut sedang berusaha menjalin hubungan sosial yang baik setelah peperangan. Pemimpin di negara Pring -godani, Raden Gatotkaca, telah meninggal dunia dan kedudukannya digantikan Raden Sasikirana (anaknya).

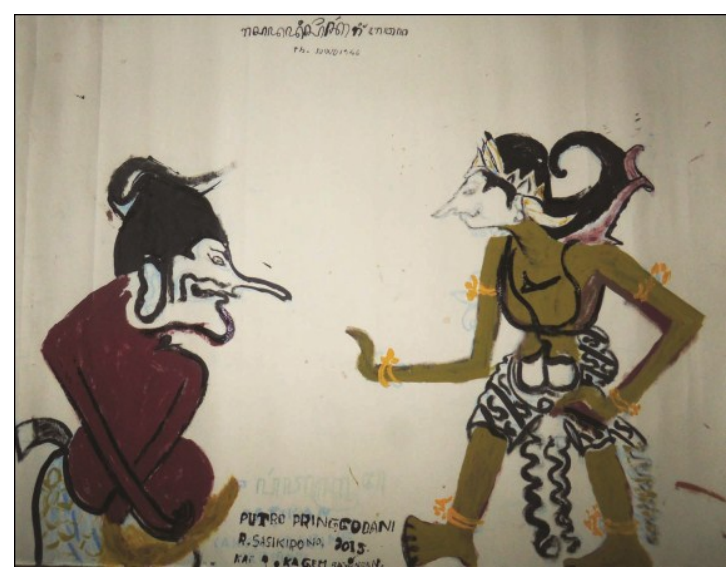

Gambar 6.

Perintah sang Raden, cat tembok dan cat besi pada kertas, $109 \mathrm{~cm}$ x $79 \mathrm{~cm}, 2014$. (Dokumentasi foto Feri Widiyanto, 2014)

Dalam masa pembenahan negara, Raden Sasikirana memberikan amanat kepada rakyatnya. Amanat tersebut disampaikan lewat abdinya, Petruk. Sebagai abdi yang patuh kepada tuannya Petruk menyampaikan amanat Raden Sasikirana kepada rakyat Pringgodani. Amanat dari Raden Sasikrana berupa perintah untuk seluruh rakyat agar menjalin kerukunan dengan 
sesama dan bekerja untuk mencukupi kebutuhan. Khusus bagi para petani dianjurkan untuk bercocok tanam dengan cara tradisional dan tetap memanfaatkan segala hasil pertanian untuk menunjang kehidupan (wawancara Suripno, 30 Maret 2015).

Gambar wayang karya Suripno yang berjudul Petruk Bertemu Istri ini merupakan adegan pertemuan antara Petruk dengan istrinya, Dewi Sebloh Lestari.

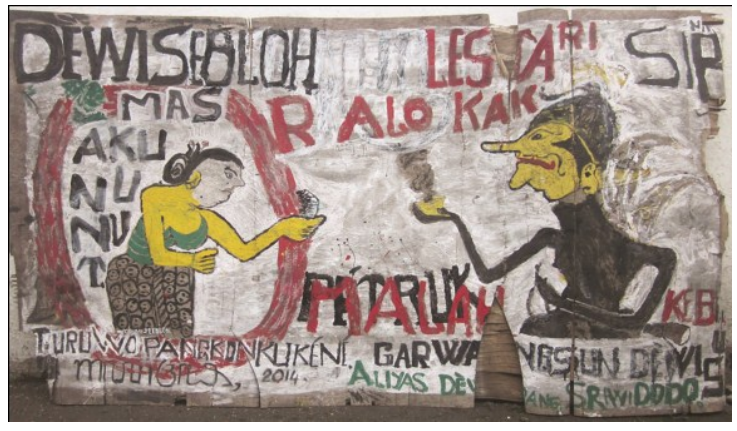

Gambar 7

Petruk Bertemu dengan Istrinya, Cat Besi pada Triplek, $200 \mathrm{~cm} \times 150 \mathrm{~cm}, 2015$ (Dokumentasi foto: Feri Widiyanto, 2015)

Dikisahkan Dewi Sebloh Lestari meminta Petruk tidur. Petruk menanggapi permintaan istrinya; mempersilakan sang istri tidur di pangkuannya. Percakapan Petruk dan Dewi Sebloh Lestari dalam karya ini diekspresikan melalui tulisan.

Karya Suripno yang berjudul Mengeti Pitulasan ini merupakan eks -presi artistik Suripno merespon peristiwa saat karya tersebut dibuat: peringatan hari kemerdekaan Negara Kesatuan Republik Indonesia. Punika nalika mengeti pitulasan tahun wingi (17 Agustus 2014).

"Kula ndherek ngeluhuraken kemerdekaan bangsa sak negarane. Muga-muga tulus, lulus nir ing sambikala," (wa-wancara Suripno, 1 Juli 2015).

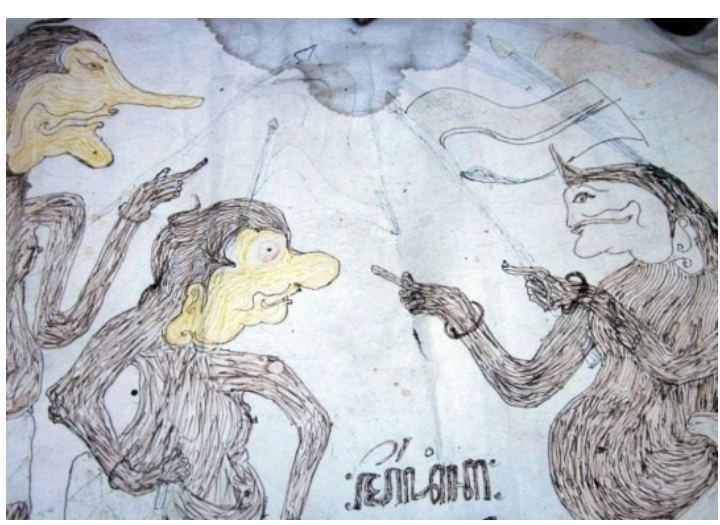

Gambar 8

Mengeti pitulasan, Spidol pada kertas, 70 $\mathrm{cm} \times 50 \mathrm{~cm}, 2014$

(Dokumentasi foto oleh: Feri Widiyanto, 2014)

Suripno, dalam karya ini bermaksud ikut menjunjung kemerdekaan bangsa dan Negara, dalam karya ini Suripno juga berharap agar bangsa ini terhindar dari bencana.

Suripno dalam karya ini juga bercerita tentang keberadaan Semar sebagai pemuka tanah Jawa. Semar memberikan nasihat kepada Gareng dan Petruk supaya menghormati orang tua. Semar nduding anake: Gareng lan Petruk, "Arepa piye-piye ya le, ojo nglalekne wong tua, wong 
tuwa kuwi kudu diajeni" (wawancara Suripno, 1 Juli 2015).

Suripno dalam karyanya yang berjudul Mengeti Pitulasan ini bermaksud mengingatkan supaya bangsa Indonesia tidak melupakan sejarah perjuangan rakyat Indonesia, leluhur, dalam memperjuangkan kemerdekaan.

Wayang purwa pada karya Suripno merupakan penghayatan batiniah Suripno atas keberadaan tokoh dan kisah pewayangan pada tradisi dan budaya Jawa. Suripno percaya bahwa "leluhur-leluhurnya" yang tergambar pada boneka wayang merupakan bentuk-bentuk ajaran, teladan dan pengayoman baginya. Kepercayaan Suripno mengenai para leluhur diekspresikannya melalui karya visual: gambar wayang karya Suripno. Estetika pada gambar wayang karya Suripno bukan lagi estetika sebagai keindahan namun rasa yang non inderawi, sensasi batiniah.

Gambar wayang yang dibuat oleh Suripno berorientasi pada penghayatan batiniah: Suripno gandrung pada wayang sehingga ia merasa terayomi ketika menggambarkan tokoh-tokoh wayang yang diidolakannya (wawancara Suripno, 22 September 2015). Suripno menggambar wayang untuk memaparkan perasaan bangga, senang dan terayomi; sensasi batiniah Suripno sebagai penghayat wayang purwa dan budaya Jawa.

Sensasi batiniah yang terdapat pada karya Suripno berkait dengan kepercayaan Suripno pada wayang purwa. "Nek kula nggambar kuwi butuhe mbeningke pikir, amarga sing digambar mbah-mbah eyang-eyang, ora nggayuh neka-neka, butuh kula gambar neng ati tentrem ngurangi pikiran ala." (wawancara Suripno, 23 September 2015).

Suripno mensyaratkan pikiran harus bersih ketika melakukan aktivitas menggambar karena yang digambar, menurut kepercayaannya, adalah para leluhur; Suripno tidak mengharap macam - macam, kebutuhannya hanya satu yaitu menggambar agar hati merasa tentram serta mengurangi pikiran buruk.

Penghayatan Suripno pada wayang purwa tidak hanya diekspresikan pada karyanya, namun penghayatan Suripno juga diekspresikannya melalui budaya kesehariannya. Misal menggambar wayang, kegemarannya menceritakan kisah dan tokoh pewayangan yang diidolakannya dan laku prihatin di seputar kawasan karaton. Budaya yang melingkupi Suripno ini terbangun dari pengalaman, penge- 
tahuan serta ngelmu bagi kepentingan batiniahnya: penghayatan pada wayang. Budaya bukan berarti "seni klasik kerajaan" namun budaya dalam arti luas dan pluralis yang mencakup budaya orang kecil dan juga unsur budaya dalam kehidupan sehari-hari (Stange, 1998: xxi).

Gambar wayang yang dibuat oleh Suripno menampakkan kecenderungan visual dari budaya Suripno sebagai penghayat wayang. Visualisasi karya-karya Suripno meski bertujuan untuk mengekspresikan keadiluhungan wayang purwa (karaton) namun hasilnya cenderung menampakkan visual wayang masyarakat Jawa tradisional di luar tembok karaton atau masyarakat pedesaan (Setyawan,2007:34). Hasil wayang yang dibuat oleh Suripno berupa wayang dengan tampilan sederhana, muncul tulisan berbahasa Jawa dan Indonesia, muncul tampilan pelangitan serta terdapat cerita carangan yang dibuat oleh Suripno.

Masyarakat di luar tembok karaton mengekspresikan visual wayang untuk kepentingan bercerita, maka visual wayang yang dihasilkan cenderung berkutat pada tema kehidupan sehari-hari atau kisah pahlawan-pahlawan dari kalangan rakyat kecil (Adisasmita. 2008: 54-71). Kecenderungan visual gambar-gam- bar wayang karya Suripno tidak mengarah pada karya seni wayang kulit purwa yang dipakai pada pementasan.

Gambar-gambar wayang karya Suripno cenderung terlihat seperti ilustrasi naskah Jawa, ilustrasi komik wayang atau lukisan kaca. Gambar wayang karya Suripno menampakkan ekspresi budaya kesehariannya: sederhana, jujur, kotor, bercerita, jelata, lucu bahkan ironi.

Estetika pada gambar wayang karya Suripno merupakan rasa (non inderawi) yang berorientasi pada per -lindungan, ketentraman dan pengayoman (sensasi batiniah). Estetika ini terbangun berdasarkan penghayatan Suripno pada wayang dalam budaya Jawa. Suripno mengekspresi -kan tokoh, kisah, ajaran, falsafah serta mitologi pewayangan sebagai budayanya. Estetika pada karyakarya Suripno terletak pada penghayatan, ironi, satir dan kejela-taan Suripno yang terbangun dari budaya kesehariannya: rasa penghayatan.

\section{SIMPULAN}

Wayang purwa memiliki pengaruh dalam kehidupan masyarakat Jawa tradisional. Sebagai produk budaya Jawa yang adiluhung (karaton) wayang memiliki konvensi atau tata cara yang berkait pada 
pemaknaan, pementasan dan bentuk visualnya. Konvensi pewayangan (visual, cerita atau pemaknaannya) dibakukan oleh karaton untuk menjaga nilai yang ada di dalamnya (falsafah, ajaran, serta terkait artistik dan estetikanya). Sebagai pusat budaya Jawa, karaton menempatkan raja pada status sosial tertinggi. Raja memiliki simbol-simbol kekuasaan yang dipuja oleh masyarakat Jawa tradisional. Selain raja juga terdapat para abdi dalem yang bekerja untuk kepentingan raja dan karaton, salah satunya adalah melestarikan tradisi dan budaya Jawa karaton (nguri-uri).

Di lingkungan karaton, wayang masih memiliki fungsi baku berdasar konvensi karaton. Wayang bukan hanya sebagai tontonan yang menghibur namun juga tuntunan terkait pada kepercayaan batiniah: ruwatan, slametan dan mitoni. Wayang yang bersumber pada tradisi dan budaya Jawa adiluhung (karaton) juga mengalami banyak perkembangan pada aspek visual, cerita atau pementasannya. Wayang pada perkembangannya menjadi lebih variatif.

Wayang dari produk yang adiluhung (karaton) menuju perkembangan kreatif produk masyarakat luas. Wayang terus berkembang ber -dasar kebutuhan, pemahaman dan kreatifitas masya-rakat.

Berbagai varian bentuk wayang yang hadir di tengah-tengah masyarakat memunculkan nilai artistik dan estetik yang baru dan agak berbeda dari sumber aslinya (karaton). Perbedaan ini muncul karena masyarakat juga memiliki kreatifitas berdasar pengalaman, pengetahuan dan pemahaman personalnya pada wayang. Wayang dalam perkembangannya (visual, cerita atau pementasannya) adalah ekspresi masyarakat dalam memaknai wayang dalam tradisi dan budaya Jawa.

Perkembangan bentuk wayang saat ini memunculkan berbagai ragam gambaran yang berbeda (yang seringkali juga di-anggap salah) jika dilihat dari konvensi karaton, salah satunya adalah gambar wayang karya Suripno.

Gambar wayang karya Suripno merupakan karya rupa yang mengangkat tema pewayangan (tokoh, kisah dan mitologi) sebagai ekspresi penghayatan Suripno pada wayang. Tidak lepas dari pengalaman, pengetahuan dan pemahaman Suripno sebagai pembuatnya, wayang yang dihasilkan cenderung berbeda dari wayang yang dilestarikan oleh karaton. Sebagai pembuat wayang, 
Suripno juga memiliki pengalaman, pengetahuan dan pemahaman yang berdasar dari kehidupannya seharihari: buruh tani, gendul kopi, pengumpul buku bekas, abdi dalem, penerjemah tulisan Jawa, penjual gambar wayang dan laku prihatin. Gambar wayang yang dibuat Suripno jauh dari konvensi karaton jika dilihat dari segi artistik dan estetikanya, meski menurutnya gambar-gambar wayang karyanya dibuat didasarkan pada konvensi karaton.

Gambar wayang yang dihasilkan oleh Suripno tidak seperti produk budaya Jawa adiluhung (wayang purwa konvensi karaton). Tampilan wayang yang dihasilkan oleh Suripno ini berupa lembaran kertas, spanduk plastik dan triplek lusuh yang bergambar figur wayang serta tulisan berbahasa (dan atau beraksara) Jawa dan berbahasa Indonesia. Gambar wayang karya Suripno cenderung lebih sederhana, diperhatikan dari segi visualnya figur -figur pewayangan yang digambar Suripno tampak cebol (pendek dan gemuk) bahkan terpotong serta tidak terdapat ornamen atau sorotan warna yang rumit. Suripno hanya menyandarkan hasil karyanya pada tembok bangunan karaton (kawasan Supit Urang) sebagai sawangan orang-orang yang lalu lalang di depannya. Karya Suripno yang tersandar pada tembok bangunan karaton nampak kotor, lusuh dan rusak. Sering juga Suripno melakukan aktivitas kesehariannya, seperti makan, minum dan tidur, di sekitar karyanya. Tidak hanya pada visual dan penyajian karyanya yang berbeda dari wayang konvensi karaton, makna wayang dalam karya-karya Suripno juga berbeda. Suripno memaknai wayang berdasarkan pengalaman, pengetahuan dan pemaham an yang ada dalam lingkup kesehariannya (budaya). Misal cerita carangan yang dibuat oleh Suripno dan munculnya nama baru pada salah satu figur wayang buatannya (Dewi Sebloh). Upaya Suripno dalam membuat cerita carangan dalam karyanya merupakan ekspresi Suripno atas peristiwa, aktivitas dan permasalahan yang terjadi dalam kehidupannya sehari-hari.

Tampilan hasil gambar wayang yang dibuat oleh Suripno tampak terbatas dari kesan indah (inderawi) meski Suripno mengikuti visual wayang konvensi Surakarta. Gambar wayang yang dihasilkan oleh Suripno cenderung seperti visual wayang yang dibuat oleh masyarakat di luar tembok karaton, yang sering terlihat pada ilustrasi 
naskah Jawa, ilustrasi komik dan lukisan kaca yang bertema panakawan.

Gambar wayang karya Suripno bukan dibuat untuk mengekspresikan keindahan (inderawi) yang ada pada wayang. Gambar wayang yang dibuat oleh Suripno untuk mengekspresikan sensasi batiniah Suripno. Rasa pada karya Suripno ini bukan rasa yang inderawi namun non inderawi: penghayatan, ironi, kejelataan bahkan pengayoman. Suripno mengekspresikan rasa (non inderawi) berdasar dari budaya kesehariannya: penghayatannya pada wayang. Estetika pada karyakarya Suripno merupakan estetika sebagai rasa yang terdapat pada kepercayaan batiniah Suripno sebagai penghayat wayang dalam budaya Jawa.

*Penulis adalah lulusan prodi. Seni Murni ISI Surakarta.

\section{DAFTAR PUSTAKA}

\section{Sumber Buku}

Bambang Suwarno. 1999. Wanda Kaitanya Dengan Pertunjukan Wayan Kulit Purwa Masa Kini. Laporan penelitian tidak diterbitkan.Yogyakarta: Universitas Gajah Mada.
Budiono Heru Satoto. 2008 Simbolisme Jawa. Yogyakarta: Ombak.

Dharsono Sony Kartika. 2012.Seni Lukis Wayang. Surakarta: ISI Press.

James P Spradley. 2006. Metode Etnografi. Yogyakarta: Tiara Wacana.

Kuntowidjoyo. 2004. Raja, Priyayi Dan Kawulo. Yogyakarta: Ombak.

Mikke Sutanto. 2012. Diksi Rupa, Yogyakarta: DictiArt Lab\& Bali: Djagad Art House.

Paul Stange. 1998. Politik Perhatian: Rasa dalam kebudayaan Jawa. Yogyakarta: Lkis.

Purwadi. 2013. Mengenal Gambar Tokoh Wayang Purwa dan Keterangannya. Sukoharjo: Cv. Cendrawasih.

Sartono Kartodirjo., A. Sudewo \& Suharjo Hatmosuprobo. $1987 . \quad$ Perkembangan Peradaban Priyayi. Yogyakarta: GadjahMada University Press.

Yustinus popo Hari Cahyono. 2010. Rampogan Wanara Kreasi Ki Bambang Suwarno. Laporan penelitian tidak diterbitkan. Surakarta: Institut Seni Indonesia Surakarta.

\section{Sumber Katalog}

Katalog Pameran TjapPetruk Bentara Budaya, Yogyakarta, 2004. 
Katalog Pameran tunggal Herlam bang Bayu Aji, Wayang Rajakaya, 2007.

\section{Media Masa Internet}

"37 Tahun mengabdi di Keraton Surakarta, Mbah Ripno ogah pensiun". Merdeka. Com, di akses oleh: Feri widiyanto, pada tanggal 15 Maret 2015 jam 14.55 wib. melalui alamat:

http://iorg.merdeka.com/peristiwa/37

-tahun-mengabdi-di-keraton-

surakarta-mbah-ripno-ogah-

pensiun.html

"Menyusuri Jalan Sunyi Sang Penjaga Budaya". Joglo Semar, Kamis 7/11/2013. di akses oleh: Feri widiyanto, pada tanggal 15 Maret 2015 jam 14.55 wib. melalui alamat:

http://edisicetak.joglosemar.co/berita /menyusuri-jalan-sunyi-sangpenjaga-budaya-160696.html

\section{Sumber Internet}

Atmira Satya Mahardika. 2011. Peran Abdi Dalem dalam Melestarikan Budaya di Keraton Surakarta, tesis pada Fakultas IImu Sosial, Universitas Negeri Semarang, (http://lib.unnes.ac.id/8288/ diunduh oleh Feri Widiyanto pada tanggal 13 agustus 2015).

Bing Bedjo Tanudjaya. 2004. Punakawan Sebagai Media Komunikasi Visual, Nirmana, (On line) Vol. 6, No. 1, Januari 2004. Hal: 47, (nirmana.petra. ac.id/index.php/dkv/article/view File/16251/16243 diunduh oleh Feri Widiyanto pada tanggal 13 agustus 2015).
Dwi Wahyudiarto. 2006. Makna Tari Canthangbalung dalam Upacara Gunungan di Kra ton Surakarta, Harmonia: Journal of Art Reseach and Education, (Online), Vol. 7 no.3,

(http://journal.unnes.ac.id/a rtikel nju/harmonia/739 diunduh oleh Feri Widiyanto pada tanggal 23 desember 2014).

Nuning Damayanti Adisasmito. 2008. Karakter Visual dan Gaya Ilustrasi Naskah Lama di Jawa Periode 1800-1920, Jour nal of Visual Art and Design: Institut Teknologi Bandung, (Online) Vol. 2, No. 1, Hal: 62, (http://journals.

itb.ac.id/index.php/ivad/article/ view/680 diunduh oleh Feri Widiyanto pada tanggal 23 desember 2014).

Teguh Sutrisno. 2009. Refleksi Kehidupan Abdi Dalem Bedhaya Keraton Kasunanan Surakarta, Greget: Jurnal Pengetahuan dan Penciptaan Tari,(Online) Vol 8 juli 2009 (jurnal.isi-ska.ac.id/index.php/ greget/article/download/34/32 diunduh oleh Feri Widiyanto pada tanggal 13 agustus 2015).

Timbul Subagya. 2013. Nilai-Nilai Estetis Bentuk Wayang Kulit, Gelar: Jurnal Seni Budaya, (Online), Vol 11. Hal: 266, (jurnal.isi-ska.ac.id/index.php/ gelar/article/download/711/634 diunduh oleh Feri Widiyanto pada tanggal 29 agustus 2015). 